\title{
Correction to: Forkhead Box F1 promotes breast cancer cell migration by upregulating lysyl oxidase and suppressing Smad2/3 signaling
}

\author{
Gisela Nilsson ${ }^{1,2}$ and Marie Kannius-Janson ${ }^{2 *}$
}

\section{Correction to: BMC Cancer https://doi.org/10.1186/s12885-016-2196-2}

Following publication of the original article [1], the authors reported an error in Fig. $6 \mathrm{c}$ and in the figure legends for Fig. 5c and Fig. 6c.

In Fig. $\mathbf{6 c}$ there has been a duplication of the western blot panel for p130Cas resulting in that the same panel is shown for Smad2/3 and p130Cas. This has now been changed in the figure and the correct panel for Smad2/3 has now been included. Fig. 6 is supplied below.

In figure legend $\mathbf{5 c}$ the text:

c, upper panel, western blot analysis of whole cell extracts from HC11 and HC11FoxF1 cells probed with phosphospecific p130Cas antibody, stripped and re-probed with p130Cas and $\alpha$-tubulin antibodies.

has been corrected to:

c, upper panel, western blot analysis of whole cell extracts from HC11 and HC11FoxF1 cells probed with either phosphospecific p130Cas antibody or p130Cas and $\alpha$-tubulin antibodies.

In figure legend $\mathbf{6} c$ the text:

c, upper panel, western blot analysis of HC11FoxF1 cells untreated or treated with FAK inhibitor (FAK inhibitor 14, Santa Cruz) $20 \mu \mathrm{M}$ for $1 \mathrm{~h}$. The effect of the FAK inhibitor was confirmed by analyzing FAK phosphorylation levels at Y396 (data not shown). Whole cell extracts were probed with FAK-p ${ }^{\mathrm{Y} 576}$ antibody, stripped and re-probed FAK and $\alpha$-tubulin antibodies. Nuclear extracts were probed with phosphospecific Smad2 and HDAC-1 antibodies. Whole cell extracts were probed with phosphospecific p130Cas and Smad2/3 antibodies, stripped and re-probed with p130Cas and $\alpha$-tubulin antibodies.

has been corrected to:

c, upper panel, western blot analysis of HC11FoxF1 cells untreated or treated with FAK inhibitor (FAK inhibitor 14, Santa Cruz) $20 \mu \mathrm{M}$ for $1 \mathrm{~h}$. The effect of the FAK inhibitor was confirmed by analyzing FAK phosphorylation levels at Y396 (data not shown). Whole cell extracts were probed with either FAK-p ${ }^{\mathrm{Y} 576}$ antibody or FAK and $\alpha$-tubulin antibodies. Nuclear extracts were probed with phosphospecific Smad2 and HDAC-1 antibodies. Whole cell extracts were probed with phosphospecific p130Cas and Smad2/3 antibodies, stripped and re-probed with p130Cas and $\alpha$-tubulin antibodies.

\section{Author details}

'Department of Medical Biochemistry and Cell Biology, Institute of Biomedicine, University of Gothenburg, Box 430, SE-405 30 Gothenburg, Sweden. ${ }^{2}$ Department of Chemistry and Molecular Biology, University of Gothenburg, Box 462, SE-405 30 Gothenburg, Sweden.

Published online: 23 January 2020

\section{Reference}

1. Nilsson G, Kannius-Janson M. Forkhead Box F1 promotes breast cancer cell migration by upregulating lysyl oxidase and suppressing Smad2/3 signaling. BMC Cancer. 2016;16:142. https://doi.org/10.1186/s12885-016-2196-2.

* Correspondence: marie.kanniusjanson@cmb.gu.se

'Department of Chemistry and Molecular Biology, University of Gothenburg, Box 462, SE-405 30 Gothenburg, Sweden

Full list of author information is available at the end of the article

(c) The Author(s). 2020 Open Access This article is distributed under the terms of the Creative Commons Attribution 4.0 International License (http://creativecommons.org/licenses/by/4.0/), which permits unrestricted use, distribution, and reproduction in any medium, provided you give appropriate credit to the original author(s) and the source, provide a link to the Creative Commons license, and indicate if changes were made. The Creative Commons Public Domain Dedication waiver (http://creativecommons.org/publicdomain/zero/1.0/) applies to the data made available in this article, unless otherwise stated. 
A
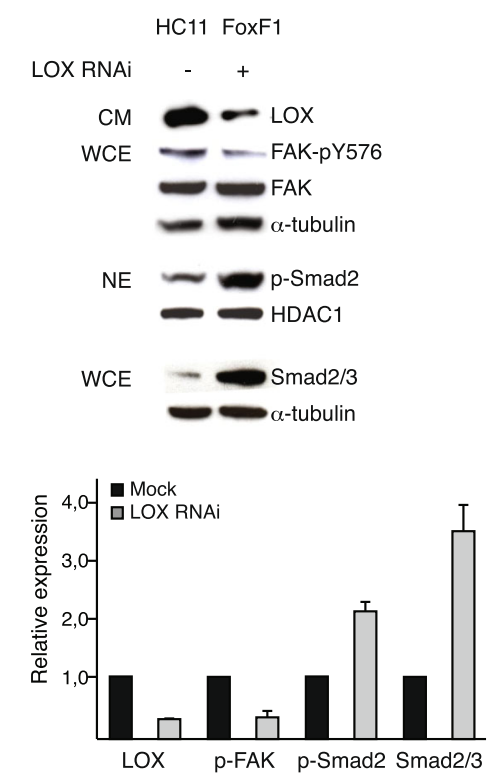

C
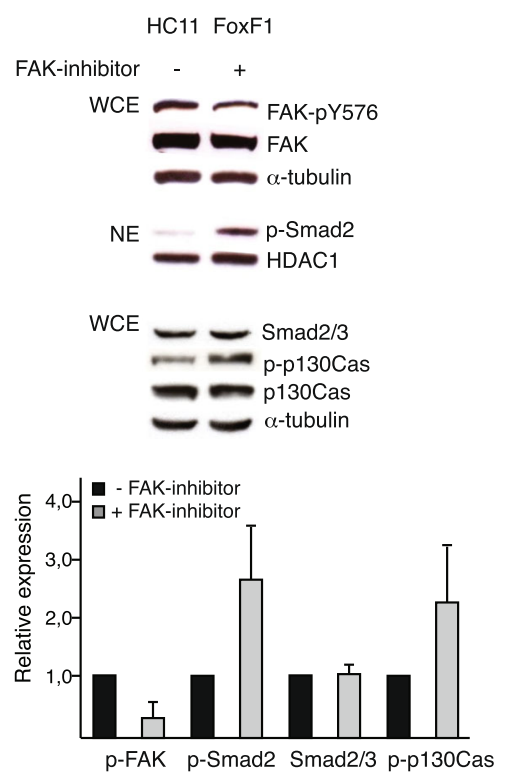

E
$\mathbf{B}$

HC11 FoxF1
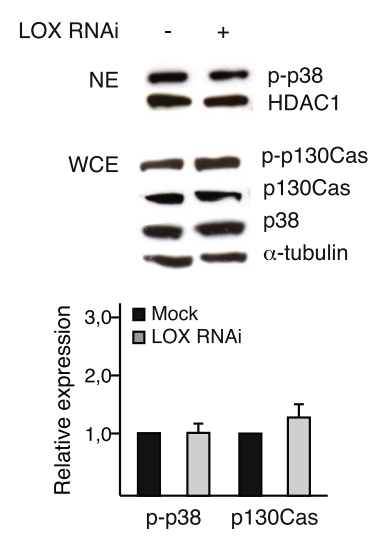

D

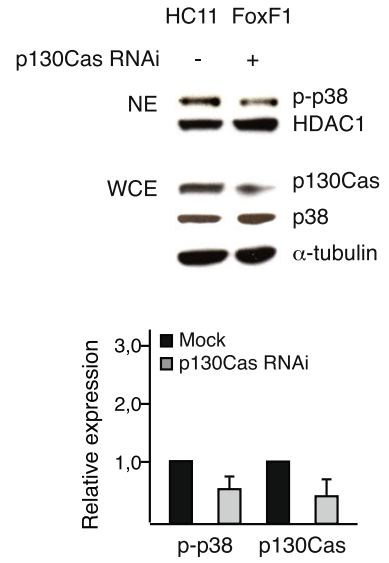

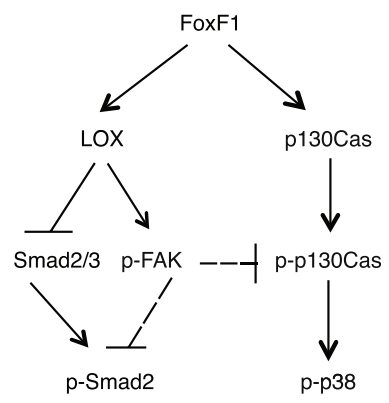

Fig. 6 FoxF1 represses Smad2 by a LOX- and FAK-dependent mechanism. a-b, upper panels, western blot analysis of HC11FoxF1 cells, mocktreated or transfected with LOX siRNA. Supernatants of cultures (CM) were probed with LOX antibody, whole cell extracts (WCE) were probed with phosphospecific antibody FAK-p ${ }^{Y 576}$ and a-tubulin antibodies, stripped and re-probed with FAK antibody. Nuclear extracts (NE) were probed with phosphospecific Smad2 antibody, stripped and re-probed with HDAC-1 antibody. Total levels of Smad2/3 were analyzed in whole cell extracts (a). Nuclear extracts were probed with phosphospecific p38 and HDAC-1 antibodies. Whole cell extracts were probed with phosphospecific p130Cas and p38 antibodies, stripped and re-probed with p130Cas and a-tubulin antibodies (b). c, upper panel, western blot analysis of HC11FoxF1 cells untreated or treated with FAK inhibitor (FAK inhibitor 14, Santa Cruz) $20 \mu \mathrm{M}$ for $1 \mathrm{~h}$. The effect of the FAK inhibitor was confirmed by analyzing FAK phosphorylation levels at Y396 (data not shown). Whole cell extracts were probed with FAK-p ${ }^{\text {Y576 }}$ antibody, stripped and re-probed FAK and a-tubulin antibodies. Nuclear extracts were probed with phosphospecific Smad2 and HDAC-1 antibodies. Whole cell extracts were probed with phosphospecific p130Cas and Smad2/3 antibodies, stripped and re-probed with p130Cas and a-tubulin antibodies. d, upper panel, western blot analysis of HC11FoxF1 cells mock-treated or transfected with p130Cas siRNA. Nuclear extracts were probed with phosphospecific p38 antibody, washed, blocked and re-probed with HDAC-1 antibody. Whole cell extracts were probed with p130Cas and p38 antibodies, washed, blocked and re-probed with a-tubulin antibody. a-d, lower panels show densitometry. e, summary of signaling events regulated by FoxF1 